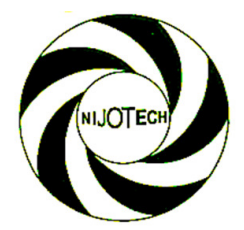

Nigerian Journal of Technology (NIJOTECH)

Vol. 35, No. 1, January 2016, pp. 48 - 53

Copyright@ Faculty of Engineering, University of Nigeria, Nsukka,

Print ISSN: 0331-8443, Electronic ISSN: 2467-8821

www.nijotech.com

http://dx.doi.org/10.4314/njt.v35i1.8

\title{
PERFORMANCE EVALUATION OF SOME LOCALLY FABRICATED COOKSTOVES IN MUBI, ADAMAWA STATE, NIGERIA
}

\author{
T. Abasiryu ${ }^{1}$, A. Ayuba ${ }^{2}$ and A. E. Zira ${ }^{3}$ \\ 1,2,3 Department of Mechanical Engineering, Federal Polytechnic, Mubi, Adamawa State, NiGERIA \\ Email addresses:1 birdling1977@yahoo.co.uk,2enochz.ayuba@yahoo.com,3arhyelayuba@gmail.com
}

\begin{abstract}
In this study, four solid fuel household cook-stoves in Mubi, Adamawa state were tested for performance using the water Boiling Test (WBT) protocol. Results from the study showed that metal charcoal stove had the highest efficiency of $20.02 \%$, followed by clay charcoal stove with $17.06 \%$, then Metal shield stove with $11.64 \%$ and the lowest is the 3-stone fire with 9.46\%. The metal charcoal stove had the lowest specific fuel consumption with the consumption value of 0.075 , then clay charcoal stove with 0.100 , followed by Metal Shield stove with 0.175 and the 3 - stone stove with the value of 0.225 . The metal shield stove had the fastest time to boil $2 \mathrm{~kg}$ of water at 12 minutes 30 seconds, while clay charcoal stove had the least time of 21 minutes 51 seconds to boil the same quantity of water. Values obtained for burn rates and fire power were $0.0285 \mathrm{~kg} / \mathrm{min}, 0.028 \mathrm{~kg} / \mathrm{min}, 0.008 \mathrm{~kg} / \mathrm{min}, 0.009 \mathrm{~kg}$, and $0.525 \mathrm{~W}, 0.516 \mathrm{~W}, 0.225 \mathrm{~W}, 0.253 \mathrm{~W}$ for 3 - stone stove, metal shield, metal charcoal and clay charcoal stoves respectively. In general, results from the testing showed that some stoves currently used in Mubi have improved fuel efficiency and higher thermal efficiency compared with the traditional cooking method. Better solid fuel cookstoves implies reduced fuel use, reduced deforestation and reduced air pollution.
\end{abstract}

Keywords: Cookstoves, cookstove performance, water boiling test, wood stove, charcoal stove

\section{INTRODUCTION}

Around two-thirds of the population of developing countries, as at 2000 , is still primarily dependent on bio-fuels for domestic use [1]. In Nigeria, seventy-two percent of the population depends on traditional fuel wood for cooking [2]. To achieve these tasks, they mostly use the traditional three-stone cook stove for cooking. With increase in technological researches, one would expect Nigerians to have adopted new technologies in cooking and heating [3].

Solid fuels include wood, charcoal, coal, crop residues, other biomass, animal dung, and various wastes [4]. In addition to the solid fuels, other commercial cooking, boiling and heating fuels and energy available in Nigeria are kerosene, cooking gas and electricity. Despite many options of cooking and heating, studies carried out by $[5,6,7,8]$, on household energy demands and consumption, showed that houses mainly depend on fuel wood for domestic use. This is due to lack of access to electricity or the poor power supply situation in Nigeria, which hinders the use of electric cooking, heating and boiling devices. Also the inadequate supply of kerosene, high kerosene cost and low kerosene/gas stoves, leads to adaptation and use of local cooking practice.

The common fuel woods found in Mubi and its environs are: Anogeisus leiocarpus ("Marke"), Terminalia glucosceus ("Baushe"), Azandiranchta Indica ("Nim"), Tamarindus Indica ("Tsamiya"), Parkiaclapertoniana ("Dorawa"), Prosopic Africana ("Kirya") and charcoal among others. The calorific values of these fuel woods range between 15MJ and 18MJ. Adeyemi et al [9] and Foley et al [10], gives the net calorific value of $1 \mathrm{~kg}$ charcoal to be $30 \mathrm{MJ}$.

Among the various technologies introduced in the realm of efficient household heating and cooking methods, stoves are the most popular and widespread in both urban and rural communities. Especially in developing countries, stoves occupy a central place in health, environmental, economic and social domain of life. By improving the efficiency of wood burning stoves, the amount of toxic smoke produced can be reduced and associated health risks minimized. In view of these and other concerns, a good cooking 
stove is defined as one that meets technical, scientific, safety, high combustion emissions, ergonomics and structural stability standards [11].

Many people use the traditional stove for cooking, boiling and heating. Therefore, efforts to improve the performance of cooking stoves have been increasingly popular especially in developing countries. Improved cook stoves (ICS) come in different forms and sizes and can be designed and built in various ways, depending on the local conditions. Many of these stoves are made of mud or sand since both are free and readily available [12].

It is known that smoke emitted from open combustion causes serious air pollution and has a negative impact on health of the users, especially women and children. The World Health Organization (WHO), estimates that more than 1.5 million people die annually due to combustion of solid fuels [13], and according to reports by International Center for Energy, Environment and Development (ICEED), Nigeria experiences one of the highest number of smoke related deaths in the world[14]. Although the most effective way to address indoor air pollution created by smoke would be to switch to cleaner gaseous and liquid fuels (such as ethanol/methanol or biogas stoves), it is likely that for vast majority of the poor, improved biomass fired stoves will remain the most important option for many years to come [11].

Traditional wood stoves in Nigeria have been classified into four types $[15,16]$ : the three stone, metal cylinder shaped, metal tripod and clay type. But over the years different cookstoves have been developed to improve performance but test results have not been reported. The objectives of this study are to determine if some of the cookstoves produced in Mubi have high thermal efficiency, lower smoke emission compared with the traditional 3-stone fire and to provide other useful information.

\section{THEORETICAL ANALYSIS}

The water boiling test (WBT) method can be used to assess the thermal efficiency $(\mathrm{H})$, the fire power $(\mathrm{P})$, the specific fuel consumption (SC) and the burn rate (F) of stoves [17]. Several formulae relating to cookstove performance have been developed. For this study the methods based on the approach by $[18,19]$ would be used.

1. Thermal efficiency $(\mathrm{H})$ is the ratio of the work done by heating and evaporating water to the energy consumed by burning wood [18].Mathematically,

$$
H=\frac{4.186 W_{W}\left(T_{f-} T_{i}\right)+2260 W_{V}}{\mathrm{~F}_{\mathrm{d}} \times \mathrm{LHV}}
$$

Here, $W_{w}$ is the mass of water in the potin $\mathrm{Kg}$, $4.186 \mathrm{~J} / \mathrm{g}^{0} \mathrm{C}$ the specific heat of water, $\left(\mathrm{T}_{\mathrm{f}}-\mathrm{T}_{\mathrm{i}}\right)$ the change in water temperature in ${ }^{\circ} \mathrm{C},\left(\mathrm{W}_{\mathrm{v}}\right)$ is the of the amount of water evaporated from the pot, while $2260 \mathrm{~J} / \mathrm{g}$ is the latent heat of evaporation of water. The dry wood equivalent consumed during each phase of the test is $\left(\mathrm{f}_{\mathrm{d}}\right)$ in $\mathrm{Kg}$ and the LHV, lower heating value (also called net heating value) of the fuel.

2. Fire Power $(\mathrm{P})$ is the ratio of the wood energy consumed by the stove per unit time $(\mathrm{W})$ during each phase of the test [18].Mathematically,

$$
P=\frac{\mathrm{f}_{\mathrm{d}} \times \mathrm{LHV}}{60\left(\mathrm{t}_{\mathrm{f}}-\mathrm{t}_{\mathrm{i}}\right)}
$$

Where $\left(t_{f}-t_{i}\right)$ is the duration of the specific test phase. 3. Specific fuel consumption (SC) is the ratio of the amount of fuelwood consumed to the amount of water remaining at the end of the trial, can be defined for any number of cooking tasks, and should be considered "the fuelwood required to produce a unit output" whether the output is a boiled water, cooked beans, or loaves of bread [18].Mathematically

$S C=\frac{\mathrm{f}_{\mathrm{d}}}{\mathrm{W}_{\mathrm{Wf}}}$

Where, $\mathrm{W}_{\mathrm{wf}}$ is the mass of water boiled in $\mathrm{Kg}$. In this case specific fuel consumption refers to a measure of the amount of wood required to produce $2 \mathrm{~kg}$ of boiling water.

4. Burn rate $(F)$ is the measure of fuel consumption to bring water to boil. It is the ratio of fuel consumed to duration of the test [19].Mathematically,

$$
F=\frac{1}{\mathrm{t}} \times \frac{100\left(\mathrm{~W}_{\mathrm{i}}-\mathrm{W}_{\mathrm{f}}\right)}{100+\mathrm{M}}
$$

where, $\mathrm{t}$ is the total time taken for burning fuel, $\mathrm{W}_{\mathrm{i}}$ is the initial mass of the fuel before burningin $\mathrm{Kg}, \mathrm{W}_{\mathrm{f}}$ is the mass of fuel after burning in Kgand $M$ is the moisture content.

$$
\begin{aligned}
& \text { moisture content }(x) \\
& =\frac{\text { mass of moiture in wood sample }}{\text { mass of oven - dry wood sample }}
\end{aligned}
$$

\section{MATERIALS AND METHODS}

\subsection{Materials}

Local artisans in Mubi make use of locally available materials such as sand, clay, water and sheet metals to construct cookstoves of different shapes and sizes for household use. The stoves that were tested in this study are shown in figures $1-4$, which are; 3 - stone stove, metal shield stove, metal charcoal stove and clay charcoal stove. The fuelwood and charcoal used 
were bought from local sellers in Mubi metropolis. These represent locally dominant wood species typically used for cooking and heating in all seasons. The same type of fuel was used. The measuring apparatus used were weighing balance, mercury-inglass thermometer, stopwatch and bomb calorimeter.

\subsection{Methods}

The water boiling test (WBT), stove performance test protocol version 1.5 [20] was used in this study to measure performance during operation of the stoves. This method has three components: a test at high power that is conducted with cold and hot start conditions and a test at low power that begins immediately after the hot start phase. In this study, the high power test was conducted with the cold start phase to determine the thermal efficiency, fire power, specific fuel consumption and the burn rate of the various stoves. The water boiling test procedure is described below

i. The pots are weighed empty and dry, then the weights are recorded

ii The pots are filled with water to $2 / 3$ of their capacity, their new weights are taken and recorded

iii. A quantity of wood not more than twice the estimated needed amount Taken, weighted, and its weight recorded.

iv. A thermometer was placed in each pot and the water temperature may be measured at the center, about $1 \mathrm{~cm}$ from the bottom. The water temperature was recorded.

v. A record of the time at which water in the first pot comes to full boil was taken

vi. At this point, the following rapidly done:

- All wood from the stove was removed and any charcoal knocked off. The Weight the wood, together with the unused wood from the previously weighted supply was taken.

- The Weight of all charcoal was separately taken.

- A Record the water temperature from each pot was taken.

- Each pot, with its water was weighted.

- The charcoal, burning wood and pots were returned to the stove to begin the "low power "phase of the test.

i. The charcoal and all remaining wood was recovered and weighted separately, the weights are recorded

ii. The weight of each pot with its remaining water was taken and recorded
The stoves were tested in the out-door environment to match the cooking method mostly used by the people in Mubi. The test was conducted in Yelwa ward, Mubi metropolis of Adamawa State. Each stove was loaded with the required quantity of fuelwood or charcoal, and sprinkled with $10 \mathrm{ml}$ of kerosene to aid ignition. A Pot without lid was filled with $2 \mathrm{~kg}$ of water and placed on the charged stove and was observed till boiling. At boiling, the pot was removed from the stove and the fire was immediately quenched. The measurements taken before, during and after the experiment include: the calorific value of fuels, the moisture content of fuels, the mass of the pot, the initial mass of fuel, the mass of fuel remaining, the mass of water in the pot at the beginning and end of the test phase, temperature of water at the beginning and end phase and the time taken to boil the water. Each experiment was repeated four times and average results recorded.

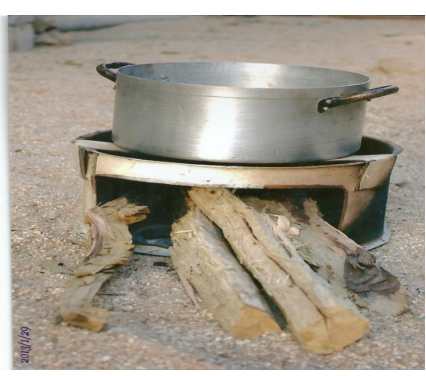

Figure 1: WBT on 3 - stone fire

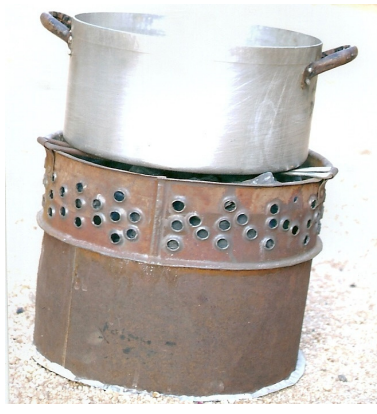

Figure 3: WBT on Metal Charcoal Stove

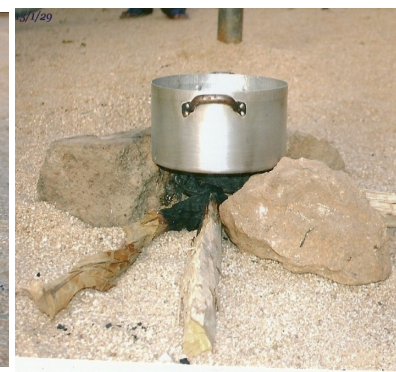

Figure 2: WBT on Metal

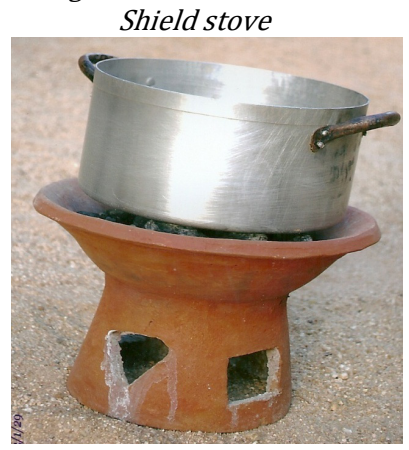

Figure 4: WBT on Clay Charcoal Stove

\section{RESULTS AND DISCUSSIONS}

The moisture content was measured to be $9.6 \%$ for the fuelwood. The charcoal which is the byproduct of the combustion of wood has a moisture content of $5.2 \%$. The calorific value of fuelwood was determined as $18400 \mathrm{KJ} / \mathrm{kg}$ and for charcoal was $27600 \mathrm{KJ} / \mathrm{kg}$. Results of the four stoves tested are summarized for easier comparison in Table 1; the time to boil, thermal efficiencies and specific fuel consumptions for the four stoves tested are also presented as bar graphs in Figs 5,6 and 7 respectively. 
Table 1: Water Boiling Test (WBT) Results for the various stoves tested.

\begin{tabular}{lcccc}
\hline Parameters & 3-stone fire & Metal shield stove & Metal charcoal stove & Clay charcoal stove \\
\hline Mass of pot $(\mathrm{kg})$ & 0.35 & 0.35 & 0.35 & 0.35 \\
Mass of stove $(\mathrm{kg})$ & 0.00 & 0.75 & 1.15 & 3.05 \\
Initial mass of fuel $(\mathrm{kg})$ & 3.15 & 2.70 & 1.10 & 0.60 \\
Final mass of fuel $(\mathrm{kg})$ & 2.70 & 2.35 & 0.95 & 0.40 \\
Mass of fuel consumed $(\mathrm{kg})$ & 0.45 & 0.35 & 0.15 & 0.20 \\
Initial temperature of water $\left({ }^{\circ} \mathrm{C}\right)$ & 27.0 & 27.0 & 27.0 & 27.0 \\
Final temperature of water $\left({ }^{\circ} \mathrm{C}\right)$ & 99.0 & 99.0 & 99.0 & 99.0 \\
Initial mass of water $(\mathrm{kg})$ & 2.00 & 2.00 & 2.00 & 2.00 \\
Final mass of water $(\mathrm{kg})$ & 1.920 & 1.935 & 1.900 & 1.850 \\
Duration for boiling water $(\mathrm{min})$ & 15.8 & 12.5 & 18.4 & 21.9 \\
Fire power $(\mathrm{W})$ & 0.525 & 0.516 & 0.225 & 0.253 \\
Specific fuel consumption & 0.225 & 0.175 & 0.075 & 0.100 \\
Burn rate $(\mathrm{kg} / \mathrm{min})$ & 0.0285 & 0.028 & 0.008 & 0.009 \\
Thermal efficiency $(\%)$ & 9.46 & 11.64 & 20.02 & 17.06 \\
\hline
\end{tabular}

Table 2: Cost of stove

\begin{tabular}{ccc}
\hline Type of stove & Types of fuel & Cost in (Naira) \\
\hline 3-stove fire & Wood & 0.00 \\
Metal shield & Wood & 200 \\
Metal charcoal & Charcoal & 300 \\
Clay charcoal & Charcoal & 350 \\
\hline
\end{tabular}

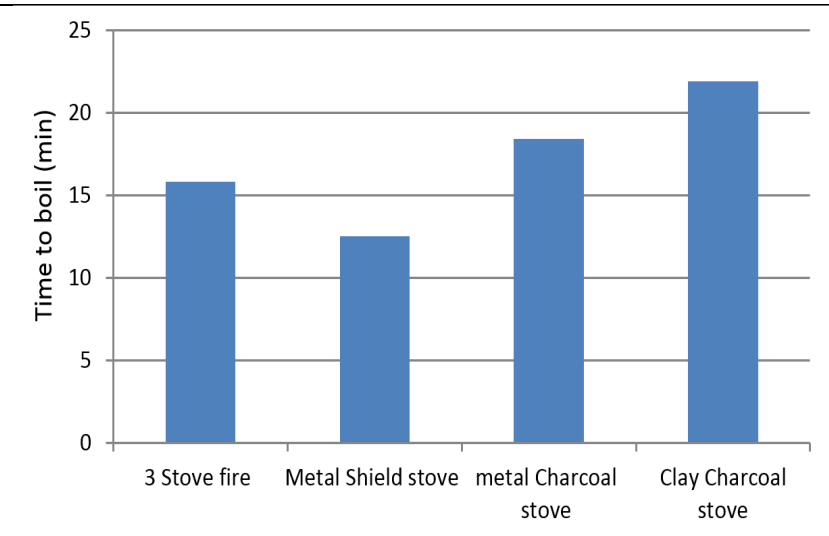

Fig. 5: Time to Boil

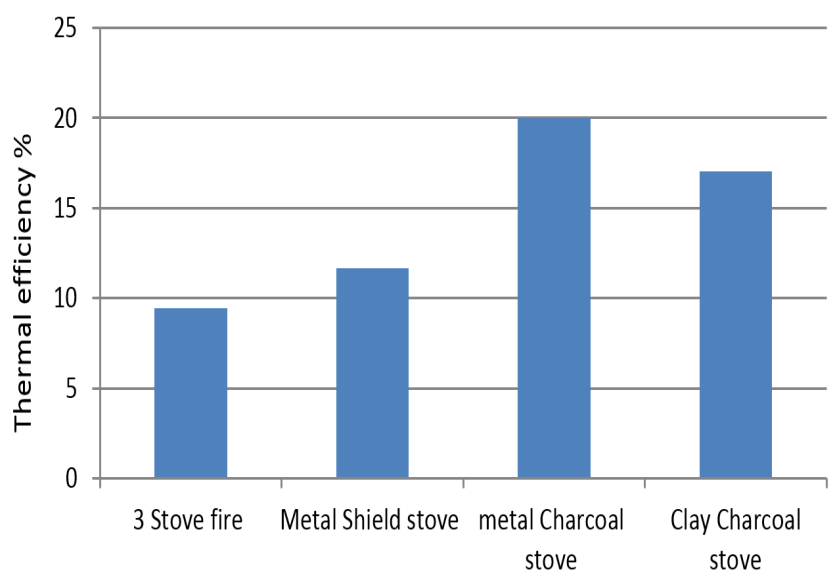

Fig. 6: Thermal Efficiency

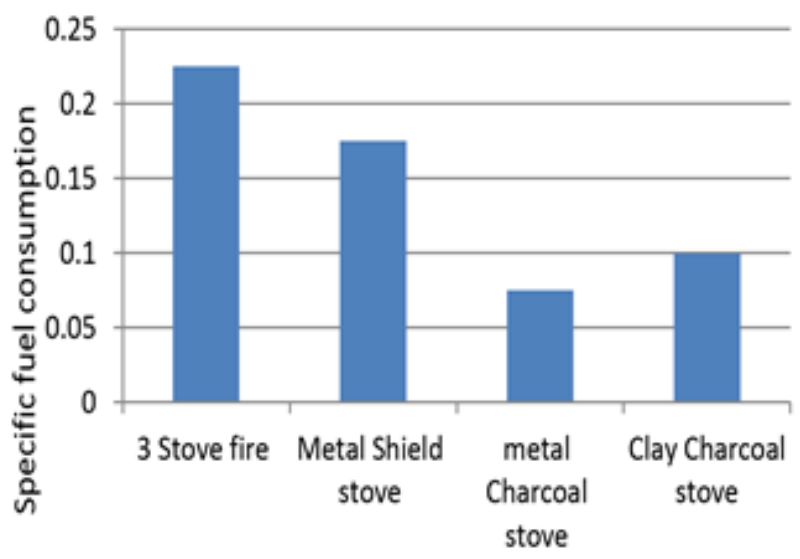

Fig. 7: Specific Fuel Consumption

The 3-stone stove has a specific fuel consumption of 0.225 , thermal efficiency of $9.46 \%$, and the time to boil of $15 \mathrm{~min}, 48 \mathrm{sec}$. The fire power and burn rate were obtained as $0.525 \mathrm{~W}$ and $0.0285 \mathrm{~kg} / \mathrm{min}$ respectively as shown in table 1 . Table 2 gives the cost of each stove. The 3-stone fire arrangement has no cost, since it is just getting 3 suitable stones. This stove took a time to boil which is quite good, but not as fast as the metal shield stove. Thermal efficiency is low and specific fuel consumption is high when compared with the other stoves tested. Visible smoke emissions were observed to be higher throughout the heating process as compared to the other stoves tested. Even though it is the cheapest, it required more attention to operate and consumed more quantity of fuel.

The Metal Shield stove has a thermal efficiency of $11.64 \%$, specific fuel consumption value of 0.175 for the test. Water spent $12 \mathrm{~min}, 30 \mathrm{sec}$ to boil on it and the 
burn rate and fire power values were $0.0280 \mathrm{~kg} / \mathrm{min}$ and 0.516 Wrespectively. The stove cost $\mathrm{N} 200$ and has a mass of $0.75 \mathrm{~kg}$ as represented in tables 1 and 2 . Compared with the 3 -stone fire, this stove has a faster time to boil, better thermal efficiency, fire power, burn rate and lower specific fuel consumption. This performance is due to the metal shield around the fire which improved the heat transfer efficiency by reducing heat loss via convection and radiation. It had similar visible smoke emission, but lower total smoke emissions, because of its shorter time to boil. The stove is simple, portable, durable and low cost, and has benefits over the traditional 3-stone fire.

The WBT performed results for each stove in table 1, shows that the metal charcoal stove tested has a thermal efficiency of $20.02 \%$, fire power of $0.225 \mathrm{~W}$, burn rate of $0.008 \mathrm{~kg} / \mathrm{min}$ and specific fuel consumption of 0.075 . The duration of $18 \mathrm{~min}$, 23sec was used in boiling the $2 \mathrm{~kg}$ of water. The stove cost $\mathrm{N} 300$ and has a mass of $1.15 \mathrm{~kg}$ as shown in table 2 . Compared with the 3-stone fire, it took longer time to boil, low specific fuel consumption and high thermal efficiency. This stove produce large amount of visible smoke at the beginning, but total smoke emission is lower when compared with 3-stone fire.

From the experimental results in table 1, the clay charcoal stove has a thermal efficiency of $17.06 \%$, the specific fuel consumption was obtained as 0.100 , the values of the firepower and burn rate were found to be $0.253 \mathrm{~W}$ and $0.009 \mathrm{~kg} / \mathrm{min}$. $21 \mathrm{~min}, 51 \mathrm{sec}$ of time was used in bringing the $2 \mathrm{~kg}$ of water to boiling. The stove costs $\mathrm{N} 350$ and has a mass of $3.05 \mathrm{~kg}$. The stove has high efficiency and lower specific fuel consumption when compared to the 3-stone stove. It took longer time to boil. This could be as a result of the thickness of the burning chamber. Overall visible smoke emissions were observed to be lower. The stove performance might be improved if the thickness of the burning chamber is reduced.

\section{CONCLUSION}

Four different types of fuelwood cookstoves have been tested for thermal efficiency, specific fuel consumption, burn rate and fire power were also determined using the water boiling test (WBT) protocol. The stove performances were evaluated from multiple perspectives because efficiency by itself is not a comprehensive indicator of performance [21]. Results from this study showed that the metal charcoal stove has the highest thermal efficiency followed by clay charcoal stove, metal shield stove and then 3-stone stove. The time to boil water showed that the clay charcoal is the least efficient while the metal shield has the highest efficiency. The 3-stone arrangement had the highest specific fuel consumption, this implies that it consumes the most fuel; it also had high visible smoke emissions compared to the other stoves tested. Burn rate and fire power tends to be higher in the 3-stone stove.

Although, kerosene stoves are available in most of the houses in Mubi, the households continued to use the traditional open fire stove. This is due to the high cost or scarcity of kerosene, large family size and the lack of adaptation to kerosene stove use among others. Hence, based on the results of the water boiling test (WBT), carried out in this study, the metal shield stove, metal charcoal stove and the clay charcoal stove can be recommended as cost effective alternatives to the 3-stone stove.

\section{REFERENCES}

1. Boy, E., Bruce, N., Smith, K.R. Hernandez, R. (2000). Fuel Efficiency of an Improved Wood - Burning Stove in Rural Guatemala: Implications for Health, Environment and Development. Energy for Sustainable Development. Vol. 4, (2), pp. 23-31.

2. ICEED (20121). Report on Expanding Access to ProPoor Energy Service in Nigeria. www.iceednigeria.org. Retrieved 03/01/2013.

3. Kulla, D. M., Folayan, C. O., and Ityona, A. (2011). Improved Woodstove Dissemination: A Step to Energy Saving, Afforestation and Health Hazard. Nigerian Journal of Engineering, Vol. 18, No.1, pp. 5965.

4. Jetter, J. J., and Kariher, P. (2009). Solid Fuel Household Cokstoves: Characterization of Performance and Emission. Biomass and Bioenergy (33): 294-305.

5. Sambo, A. S., Ali, S., and Asere, A.A. (2001). Household Energy Consumption around Bauchi Metropolis and Environs. Nigerian Journal of Tropical Engineering. Vol.2, No.1, pp. 37-48.

6. Ambore, V. Y. (2007). A Survey of Wood Usage as Fuel Energy in Bauchi Metropolis. The Gubi Journal Vol.1, No.3, pp. 370-380.

7. Moses, K .A., Samuel, R. F., and Dialo, N. (2007). A Study on Household Fuel Wood Energy Consumption in Mubi Metropolis. Unpublished HND Project. Department of Mechanical Engineering, Federal Polytechnic, Mubi, Adamawa State.

8. Yakubu, M., and Idris, M. H. (2009). Assessment of Fuel Wood Energy Consumption Pattern in Mubi Metropolis in Adamawa State of Nigeria. Journal of Engineering and Environmental Technology, Federal 
Polytechnic, Mubi, Adamawa State, Nigeria. Vol.4, pp. 49-55.

9. Adeyemi, K., Asere, A. A., and Dandakuta, D. (2008). Thermal Properties of WoodFuel found in the North East. Nigerian Journal of Solar Energy. Vol. 19, pp. 77-82.

10. Foley, G., Moses, P., and Timberlake, L. (1986). Stoves and Trees. International Institute for Environment and Development: Washington, D.C. 1-87.

11. Barnes, D. F., Openshaw, K., Smith, K.R. and Plasvander, R. (1994). What Makes People Cook with Improved Biomass Cookstoves: $A$ Comparative International Review of Stove Programs. Technical Paper Number 242, World Bank.

12. Warwick, H., and Doig, A. (2004). Smoke: The Killer in the Kitchen, Indoor Air Pollution in Developing Countries. ITDG Publishing, London.

13. Rehfuess, E. (2006). Fuel for Life: Household Energy and Health. Geneva Switzerland: World Health Organization.

14. ICEED (2012). Stopping Nigeria Going up in Smoke. www.iceednigeria.org. Retrieved 03/01/2013.

15. Akinbode, F. O. (1991). Testing the Efficiency of Nigerian Wood Stoves. Nigerian Journal of Renewable Energy. Vol. 2, No.1, pp. 43-48.
16. Akinbami, F. J. K., Salami, A. T., Siyanbola, W.O. (2003). An Intergrated Strategy for Sustainable Forest - Energy - Environment Interaction in Nigeria. Journal of Environment Management. Vol.69 (Elsevier)

17. VITA. (1985). Testing the Efficiency of Woodburning Cookstoves, International Standards. Arlington, Virginia.

18. Berrueta, V. M., Edwards, R. D., Masera, O. R. (2008). Energy Performance of Wood-Burning Cookstove in Michoacan, Mexico. Renewable Energy (33): 859870.

19. Ahuja, D. F., Joshi, V., Smith, K. R., and Venkataranma, C. (1997). Thermal Performance and Emission Characteristic of Unvented Biomass Burning Cookstove. Standard Method for Evaluation. Biomass (10): 12 .

20. Bailis, R., Ogle, D., Still, D., Smith, K.R., Edwards, R. (2004). The Water Boiling Test (WBT), Version 1.5. Berkeley, California. University of California Berkeley. August 20.

21. Visser, P. (2005). The Testing of Cook stove. Data of Water - Boiling Test as a Basisto Calculate Fuel Consumption. Energy for Sustainable Development. 9(1): 16-24. 